\title{
UNA APROXIMACIÓN DESDE LA MEMORIA HISTÓRICA AL ENFRENTAMIENTO ENTRE LAS FUERZAS ARMADAS Y LOS TERRORISTAS EN EL PERÚ DE LOS 80 Y 90 DEL SIGLO XX
}

AN APPROXIMATION FROM THE HISTORICAL MEMORY TO THE

FACING BETWEEN THE ARMED FORCES AND THE TERRORISTS IN PERU OF THE 80 AND 90 OF THE XX CENTURY

\author{
Miguel Ángel Cayuela Berruezo \\ Universidad Ricardo Palma \\ miguel.cayuela@urp.edu.pe
}

\section{RESUMEN}

En el artículo se va a analizar el enfrentamiento entre las fuerzas armadas peruanas y los grupos terroristas (Sendero Luminoso y el MRTA). Siempre desde el punto de vista de la memoria histórica y centrándonos en las principales víctimas de este enfrentamiento. Las personas civiles fueron un actor principal mientras duró la contienda. Debido a este hecho quedaron heridas abiertas en parte de la población, heridas que a día de hoy siguen vigentes. Toda paz que se consigue a través de procesos violentos siempre se considera como una paz imperfecta, lo que ocurrió en el Perú debe servir para encontrar nuevos espacios y modelos de paz.

\section{PALABRAS CLAVE}

Fuerzas armadas, paz, Sendero Luminoso, terrorismo, violencia

\begin{abstract}
The article analyzes the confrontation between Peruvian armed forces and the terrorist groups (Sendero Luminoso and the MRTA). Always from the point of view from historical memory and focusing on the main victims of this confrontation. The civil persons it was a principal actor while the fight lasted. Due to this fact there were open wounds that today continue open. The peace that achieve across violent processes always it will considers like a imperfect peace, what happened in Perú will to serve for search new spaces and models of peace.
\end{abstract}

\section{KEYWORDS}

Armed forces, peace, Sendero Luminoso, terrorism, violence. 


\section{INTRODUCCIÓN}

El Perú, como la mayoría de los países latinoamericanos estaba sumido en la llamada década perdida de los años 1980 en América del Sur. Pero para el caso peruano tuvo connotaciones más allá de lo socio económico, Perú volvía a la democracia tras la dictadura militar del Gobierno Revolucionario de la Fuerza Armada (1968 - 1980). En el Perú se volvía a confiar en un sistema democrático para que encauzase las riendas de un país que parecía perdido tras la dictadura militar.

Los países del cono sur de América Latina, estaban viviendo momentos difíciles, por una parte en Chile, la dictadura pinochetista ya estaba asentada, aunque cada vez tenía mayores problemas económicos y sociales. Argentina, también estaba en una era de incertidumbres, con la dictadura militar de Videla $(1976$ - 1981) y todo lo que conllevó este triste episodio de la historia argentina. En ambos países no se respetaron los derechos humanos a la hora de luchar contra los considerados opositores al régimen. En el caso peruano, el regreso a la democracia vino de la mano de Belaúnde Terry, venciendo en las elecciones de 1980, representando al partido político Acción Popular (AP).

Tras cinco años, Alan García sucedió a Fernando Belaúnde Terry, estando al frente del histórico partido político peruano, la Alianza Popular Revolucionaria Americana (APRA). Ambos gobiernos olvidaron los derechos humanos en la lucha contraterrorista en el Perú de los años 1980. El quinquenio de Alan García en el poder, además, fue un desastre económico de grandes proporciones, dejando al Perú en una situación económica muy delicada.

La política llevada a cabo en la década 1980 facilitó el acceso al poder a una persona que lo cambiaría todo, Alberto Fujimori. La victoria electoral de Alberto Fujimori en 1990, es gracias en gran medida al mal hacer político de Belaúnde Terry y Alan García. Ambos representaban al clásico político peruano, el cual era una persona adinerada y de rasgos europeos. El pueblo peruano se sentía defraudado por esa clase de políticos, ya que cada vez veían al Perú en peor situación económica y como los terroristas iban ganando terreno en el interior del Perú, hasta llegar a Lima. 
El final de la década de 1980 y principios de la década de 1990, nos presentaba a Sendero Luminoso asentado militarmente, un grupo terrorista lo suficientemente maduro para acometer la fase final del asalto al poder. Sendero Luminoso comenzaba a hacerse sentir en Lima, la capital peruana se presentaba como la batalla final para Sendero Luminoso.

La llegada de la década de 1990, en el Cono Sur de América Latina, vio nacer el llamado neopopulismo, liderado por Alberto Fujimori en el Perú y Carlos Menem en Argentina. En Chile, Augusto Pinochet dejaba de ser Presidente y volvía la democracia, nuevos aires democráticos y de justicia soplaban para el pueblo chileno.

Desde 1990, hasta el 2000, Alberto Fujimori gobernó el Perú sin que le temblara el pulso. Durante estos diez años se puso fin a la amenaza terrorista en gran parte del país, primeramente con la captura del líder senderista, Abimael Guzmán el 12 de septiembre de 1992, más tarde con la captura definitiva de Víctor Polay Campos, -quien fue el líder de la agrupación terrorista del Movimiento Revolucionario Túpac Amarua (MRTA), de clara orientación guevarista- en 1992 y la consecuente desaparición del MRTA en 1997, tras el éxito de la Operación Chavín de Huántar. También fue una década de estabilidad macroeconómica para el país, en donde el capitalismo hizo su entrada oficial como el sistema económico nacional, incluyéndolo dentro de la Constitución de 1993. Como se verá a lo largo del capítulo, durante la década fujimorista también se vulneraron en sucesivas ocasiones los derechos humanos.

En cuanto a la actuación de los grupos terroristas en el Perú, Sendero Luminoso y el MRTA, estuvo siempre manchada por la sangre de inocentes. Los senderistas y los emerretistas, con Abimael Guzmán y Víctor Polay Campos a la cabeza, siempre justificaron la violencia sobre el pueblo peruano como un proceso de cambio hacia una sociedad de tipo comunista. Ambos grupos terroristas tenían un proyecto diferente y una forma de actuar de igual manera diferentes.

Los grupos terroristas no dudaron en hacer uso de la fuerza bruta sometiendo a gran parte de la población peruana en el interior del país en pos de un objetivo político. Nunca dudaron en las formas para culminar sus objetivos. La paz que se instauró en el Perú no fue modélica, marcada por la violencia. Es importante dejar en claro este punto, ya que hoy en día 
todavía sigue estando presente en la selva del Perú la amenaza senderista, sobre todo en el Valle de los ríos Apurímac, Ene y Mantaro (VRAEM). Esto demuestra de que no fue una paz modélica, y que aún a día de hoy sigue estando presente el peligro senderista.

\section{LA GUERRA TOTAL, TODOS CONTRA TODOS}

Lo que sucedió en el Perú durante la década de 1980 y hasta mediados de la década de 1990, se puede considerar como una guerra total, en donde los terroristas y las Fuerzas Armadas involucraron a la población civil, haciéndola un actor más en la lucha.

Las Fuerzas Armadas, como los terroristas, se olvidaron de los derechos humanos durante la contienda. Así es como hubo matanzas y masacres por los dos bandos contra la población civil, inocente o no, realmente poco importaba, porque si para matar a un terrorista había que masacrar una comunidad campesina, finalmente se terminaría por llevarlo a cabo. Hasta finales de la década de 1980, en el interior del Perú se vivió en una tensión constante, sobre todo en zonas como las de Ayacucho o Huancavelica, en donde los terroristas y las fuerzas armadas impusieron la ley marcial.

El miedo se apoderó de la sociedad peruana, primero en la zona del interior del Perú, para más tarde llegar hasta Lima, en donde sería la batalla decisiva para Sendero Luminoso. En el Perú, vivir con miedo era algo normal durante los años que duró el terror, el actuar de los dos bandos no tenía término medio, estabas con un bando o contra él.

Desde el principio quedó claro que los terroristas no respetarían a nadie. Pero, por parte de las Fuerzas Armadas es sorprendente como obviaron los derechos humanos a la hora de luchar contra todos los terroristas.

La población fue la principal perdedora durante toda esta contienda. El Perú de la década de 1980, era un país pobre, con una inflación sobredimensionada. Si ya había que combatir la pobreza económica, al Perú también le tocó combatir contra el horror al que le abocaron Sendero Luminoso y el MRTA. 
No fue hasta la llegada de Alberto Fujimori, que Amnistía Internacional y muchas asociaciones para los derechos humanos internacionales empezaron a presionar con más insistencia en lo que estaba ocurriendo en el Perú, según declarante a la CVR de la zona de Huancavelica, República del Perú (2003):

Por aquí han pasado los terrucos, ustedes los han visto y tienen que avisar". Los reunieron con otras veinte personas que estaban por allí y los pusieron en el suelo, como era pendiente, boca abajo, en los surcos de las chacras, a todos los varones, mientras que a las mujeres jóvenes casadas y solteras las separaron y se las llevaron detrás de un morro, donde las violaron a todas. Eran cinco mujeres. Posteriormente, las mujeres aparecieron y les dijeron "ya ustedes nada tienen que hablar de esto, porque tenemos las direcciones de cada uno de ustedes, y si hay cualquier cosa ya verán (....). Fueron a recoger sus cosas y "nos fuimos a mi casa y mi esposa temblaba y no me quiso decir que le ha pasado o adónde la llevaron, bajamos a Huancavelica. (p. 313).

Como se puede observar en las declaraciones de esta persona, nos deja ante una visión aterradora de lo que pasó. Ya no solo se asesinaba a sangre fría, sino que las mujeres, niños, niñas, ancianos y ancianas se convirtieron en unas víctimas fáciles para llevar a cabo cualquier propósito. Las violaciones se encontraban a la orden del día, más en los casos de las Fuerzas Armadas, que en el de los terroristas, que también hubo casos de violaciones sobre mujeres y niñas.

\section{LA POBLACIÓN ES EL ENEMIGO}

Durante el proceso que duró el enfrentamiento, la población llegó a convertirse en uno de los principales enemigos, para las Fuerzas Armadas y para los terroristas. La población peruana, durante el conflicto se convirtió en un enemigo más.

La "guerra popular" que inició Sendero Luminoso, contra lo que ellos llamaban el "Estado viejo", dejó un país sumido en la oscuridad. Una guerra que desde el primer momento, los terroristas utilizaron a la población como un arma más contra los Fuerzas Armadas. Manipularon y secuestraron a niños y niñas para inculcarles la ideología marxista maoísta pensamiento Gonzalo. La población pasó a convertirse en uno de los principales enemigos para los senderistas, emerretistas y las Fuerzas Armadas del Perú. 
En la década de 1980, el Perú estaba sumido en el descontrol político, económico y también militar. Belaúnde Terry y Alan García, delegaron toda la organización de la lucha antiterrorista en las Fuerzas Armadas, teniendo poco o ningún protagonismo el gobierno de Terry y García en cómo afrontar la lucha contraterrorista. Quizás esa sea una de las explicaciones del porqué se obvió con tanta celeridad cualquier derecho humano en la lucha contra los grupos terroristas en el Perú. En el caso de Alberto Fujimori es distinto, ya que gracias a Vladimiro Montesinos (su mano derecha), el gobierno tenía conocimiento de cómo se estaba afrontando la lucha contraterrorista.

La década que duró el mandato de Alberto Fujimori al frente del poder en el Perú, estuvo siempre impregnada bajo el fantasma de la vulneración de los derechos humanos. Los casos de Barrios Altos y La Cantuta, deja en evidencia la política contraterrorista llevada a cabo por el gobierno de Alberto Fujimori en la primera mitad de la década de 1990. Los activistas por los derechos humanos empezaron a manifestarse a partir de la segunda mitad de la década de 1990. Las Fuerzas Armadas, tampoco respetaron en demasía los derechos humanos. Como bien lo deja en claro Hugo Relva (consejero jurídico en el proyecto de justicia internacional, para Amnistía Internacional) es una publicación del grupo al que representa:

La sala declaró que las víctimas (entre las que se encontraba un niño de ocho años) no eran terroristas, desmintiendo la injuriosa afirmación de que las ejecuciones del Grupo Colina, cuya supervisión ejercía Fujimori, habían sido la respuesta a actos de violencia inusitada cometidos por Sendero Luminoso. Esta circunstancia tiene un valor simbólico inmenso para los familiares de las víctimas, contra quienes pesaba falsamente un injusto estigma que siempre rechazaron. (RELVA, 2009: 19).

Relva se refiere a las víctimas de la masacre de Barrios Altos. La lucha contraterrorista en el Perú en la década de 1980 y 1990 dejó demasiadas heridas abiertas, que hasta el día de hoy no se han podido cerrar. Según los datos ofrecidos por la CVR, durante la contienda tuvo como víctimas civiles un total de 69.280 víctimas (República del Perú, 2003:13). El Ministerio de Justicia y Derechos Humanos también hizo un registro sobre las víctimas totales mientras duró el conflicto, mediante el Registro Único de Víctimas (RUV), con un total de víctimas mucho mayor, para la Unesco fueron 201.817 personas(Cfr. http://lum.cultura.pe/cdi/busqueda 2 de enero 2017), las víctimas civiles. Datos muy alejados el uno del otro, pero que 
dejan en claro lo que aconteció al Perú durante el enfrentamiento entre las fuerzas armadas y los terroristas.

Como apunte final para este capítulo del artículo, a continuación pondré toda la población peruana que fue víctima de la violencia militar y terrorista, facilitada por el Lugar de la Memoria, la Tolerancia y la inclusión social del Ministerios de Cultura del Perú (LUM):

Datos facilitados por la CVR: 2.218 desparecidos, 5.684 detenidos, 1.390 detenidos y desaparecidos, 908 lesionados o heridos, 2 reclutados de forma forzosa, 10.735 asesinados y ejecutados extrajudicialmente, 171 muertos en atentados, 533 muertos en enfrentamientos, 504 reclutados, 3.345 secuestrados, 5.811 torturados, 425 violadas sexualmente.(Cfr. http://lum.cultura.pe/cdi/busqueda4 de enero de 2017).

Datos facilitados por el RUV: 8.840 desapariciones forzosas, 66.083 desplazamientos forzosos, 17.209 detenciones arbitrarias, 23.910 fallecidos, 36 indebidamente requisitoriado, 47 indocumentados, 644 menores integrantes del CAD, Menores de edad que integraron un Comité de Autodefensa, obligados a luchar siendo menores de edad (18), o participar directa o indirectamente en actividades del CAD, 1.501 encarcelados siendo inocentes, 2.111 reclutados forzosamente, 13.881 secuestrados, 48.003 torturados, 1.123 víctimas con alguna discapacidad, 12.483 víctimas heridas o lesionadas, 4.471 violadas sexualmente, 1.475 violentadas sexualmente. (Cfr.http://lum.cultura.pe/cdi/busqueda4 de enero de 2017)

Todavía quedan por indagar bastantes más casos, todo no están en la base de datos del LUM, en el caso de los datos facilitados por la CVR al LUM, nos encontramos con 31.726 víctimas, cuando como hemos visto, la CVR afirma que la contienda tuvo un balance de 69.280 víctimas.

\section{LOS RONDEROS ENTRAN EN LA LUCHA, LA POBLACIÓN ACTÚA CONTRA SENDERO LUMINOSO}

La población tomó partido en la lucha a través de los ronderos, este grupo se fundó en Cuyumalca (Chota) el 29 de diciembre de 1976 (Korsbaek, 1985:185). Las primeras funciones de los ronderos fue la de proteger su poblado, es así como patrullaban todo el pueblo, desde caminos, hasta los senderos montañosos. Buscaban evitar la delincuencia 
en Cajamarca, una de las zonas más pobres históricamente del Perú. Los vecinos de Cuyumalca que decidieron llevar a cabo las rondas, lo hicieron principalmente por la sensación de abandono por parte del Estado central y su incapacidad para actuar sobre el terreno chotano.

Los ronderos tuvieron un éxito inmediato, consecuencia de ello fue la rápida expansión de ellos en la sierra del Perú. Tras 2 años se formaron al menos 300 comités de ronderos, estando principalmente en Hualgayoc, Chota y Cutervo (Gitlitz, 1985:117), además de también establecerse en Piura y Ancash. Pero, ¿Cómo entraron los ronderos a la guerra entre los terroristas y el Estado? Prácticamente los ronderos fueron empujados a ello, ya que estabas contra o con el Estado, si estabas a favor de las fuerzas del orden en la sierra del Perú, y no pertenecías a las Fuerzas Armadas, normalmente terminarías accediendo a participar como un rondero más en el conflicto.

Los ronderos desde su nacimiento estuvieron armados, pero las armas eran insuficientes para hacer frente a Sendero Luminoso en zonas como las de Ayacucho, gracias a las Fuerzas Armadas pudieron acceder a más y mejores armas. Los ronderos fueron héroes campesinos, libraron grandes batallas contra Sendero Luminoso como la victoria que tuvieron en 1990 cuando aguantaron la embestida senderista Cangari y Viru Viru (Huanta, Ayacucho) sin sufrir baja alguna. Los ronderos accedieron a trabajar conjuntamente con las Fuerzas Armadas cuando vieron que la violencia impartida por parte del ejército a la población inocente fue disminuyendo.

A pesar de sufrir bastantes bajas a manos de Sendero Luminoso, los ronderos siguieron luchando por liberar a la serranía peruana del influjo senderista. Rápidamente fueron catalogados como enemigos de la revolución para Sendero Luminoso. Normalmente cuando los senderistas conseguían asesinar a un rondero, lo mostraban al pueblo como un escarmiento, dejando en claro, que la única autoridad competente en la zona del interior peruano debía ser la de Sendero Luminoso.

Pero, los ronderos nunca se rindieron, y gracias a la inestimable ayuda de las Fuerzas Armadas, en 1991, los ronderos disponían alrededor de 10.000 escopetas Winchester modelo 1300 (RODRÍGUEZ, 2007:13), cortesía del Estado peruano. Este hecho ayudó a los ronderos para seguir luchando contra Sendero Luminoso en el interior del país. A pesar de que 
muchos campesinos también querían combatir con las mismas armas que tenían los terroristas (automáticas), las escopetas marcaron la diferencia, al añadir el factor armamentístico tenían bastante terrero ganado, pues la voluntad de actuar ya la tenían agregada desde el principio de su formación como grupo.

Los ronderos, como los militares, también hicieron uso de la violencia, es más, era la única forma de actuar que ellos veían más acorde ante el peligro senderista. Los ronderos eran milicianos sin apenas base militar, cuando no podían combatir con armas de fuego, lo hacían con piedras y en última instancia con sus propias manos. Durante el conflicto los ronderos tampoco esperaron para que una persona se demostrase si era terrorista o no, también realizaron asesinatos sin prueba alguna, más que la suposición. A pesar de ello, siempre se ganaron el respeto y la admiración de su pueblo, pues a diferencia de las Fuerzas Armadas, nunca se tomaron la justicia por su mano con tanta celeridad y arbitrariedad.

\section{LAS MASACRES LLEVADAS A CABO POR LOS GRUPOS TERRO- RISTAS Y LAS FUERZAS ARMADAS}

Sendero Luminoso, ha sido el grupo terrorista más sanguinario de la historia del Perú, con un 54\% de las muertes totales durante el conflicto entre el Estado peruano y los grupos terroristas. (República del Perú, 2003:15). La población del interior fue la más afectada por la guerra iniciada por Sendero Luminoso. En donde el pueblo ayacuchano se llevó la peor parte, el $50 \%$ de los asesinatos perpetrados por Sendero Luminoso fue en la provincia de Ayacucho. (República del Perú, 2003:16).

Sendero Luminoso llevó a cabo masacres contra población peruana, una de ella fue la de Lucanamarca, que sucedió en 1983, en la provincia de Huancasancos (Ayacucho), la consecución de la masacre dejó el balance de 69 personas muertas, las víctimas fueron hombres, niños, mujeres y ancianos (República del Perú, 2003:52). Se estima que durante la "guerra popular", según la Comisión de la Verdad y la Reconciliación (CVR), Sendero Luminoso fue autor de 215 masacres (República del Perú, 2003:21), aunque este número podría aumentar, ya que según la Fiscal que logró condenar a Abimael Guzmán, Luz Ibáñez, todavía queda mucho trabajo que hacer en cuanto a la investigación de las masacres llevadas a cabo por Sendero Luminoso. En septiembre de 2016 Luz Ibáñez afirmaba para El 
Comercio: "Masacres más grandes de Sendero recién se están descubriendo" (CF. https://elcomercio.pe/politica/justicia/masacres-grandes-senderorecien-descubriendo-399032 11 de septiembre de 2018).

La masacre senderista en Ocros (Ayacucho) acaecida el 4 de octubre de 1984, donde asesinaron a 15 civiles (República del Perú, 2003:130) en las vísperas del carnaval ayacuchano es un claro ejemplo de estos años de tensión interna en Perú. Cuatro meses después un nuevo ataque senderista causó la muerte de una docena de muertes y la destrucción de 50 casas en la misma zona.

En la "guerra popular" prácticamente estaba todo permitido, desde atacar a autoridades, hasta hacerlo contra personas bien posicionadas y acaudaladas. Así es, como Sendero Luminoso atacó también a dirigentes comunales, campesinos prósperos o como ya se ha visto, los asesinatos contra los ronderos. Todos estos asesinatos, desde la cúpula de Sendero Luminoso, se justificaban en base de que estas personas eran enemigas contra el progreso senderista, eran considerados como traidores a la nueva patria, fieles servidores del "Estado viejo".

Muchos de estos asesinatos eran dictaminados desde los llamados "juicios populares", en donde un tribunal integrado por miembros de Sendero Luminoso, decidían si la persona acusada era culpable de crímenes políticos o con la delincuencia en zonas rurales.

Atentados como el ocurrido el 16 de julio de 1992 en Lima, en el distrito de Miraflores, por desgracia era común en el Perú de la época. En el atentado murieron 18 personas y 200 personas quedaron heridas, además de atacar cuatro comisarías. Los diarios como la República titularon la portada del día siguiente: "Miraflores, jun infierno!" (La República, 17 de julio de 1992), el diario Ojo por su parte titulaba el reportaje del atentado como: "Horror, destrucción y muerte en centro de Miraflores" (Ojo, 17 de julio de 1992, p. 3).

"Para que las fuerzas de seguridad puedan tener éxito, tendrían que comenzar a matar a senderistas y no senderistas... Matan 60 personas y a lo mejor ahí hay 3 senderistas, y seguramente la policía dirá que los 60 eran senderistas" (BURT, 2011:113) Luis Cisneros Vizquerra, Ministro del Interior en la primera mitad del segundo gobierno de Belaúnde Terry, entre los 
años 1981 y 1983. Fue un general apodado gaucho, aunque para algunos más bien es recordado por ser el "Pinochet peruano" o como el "carnicero".

Las fuerzas del Estado actuaron de forma eficaz y sobre todo violentamente contra los terroristas y contra la población civil. Cuando Alan García sucedió a Belaúnde Terry en el poder, prometió preservar sobre todo los derechos humanos. Pero, a pesar de intentar hacer respetar su promesa, el 14 de agosto de 1985 ocurrió la masacre de Accomarca en Ayacucho. El ejército entró en el poblado con la excusa de que allí había una supuesta base de formación terrorista de Sendero Luminoso, el resultado fue de 62 víctimas mortales (República del Perú, 2003: 155), 23 de ellos niños, aunque la verdad que hasta el día de hoy sigue habiendo bastante polémica, ya que los familiares datan los asesinatos en 71 personas (https://www.bbc. com/mundo/noticias-america-latina-3725446929 de septiembre de 2018.). Alan García ante el escándalo que supuso esta actuación, decide destituir al comandante conjunto de las Fuerzas Armadas en la zona de Ayacucho, Telmo Hurtado, Conocido como el "Monstruo de Accomarca" y el "Carnicero de los Andes", en 1993 fue condenado a 6 años de cárcel por la masacre de Accomarca. Pero con el decreto Ley de Amnistía promulgada en 1995 por Alberto Fujimori su sentencia quedó anulada. Cuando se derrumba el régimen Fujimorista huye a Estados Unidos, será en el año 2011 cuando consigan extraditarlo y poder juzgarlo. El juicio dictaminó 25 años de prisión y el pago de 14 millones de dólares como reparación civil.

Esta victoria del nuevo gobierno sobre las Fuerzas Armadas resultó ser pírrica, ya que los militares se negaron a actuar en operaciones realizadas en el sur andino por más de nueve meses, como respuesta al órdago lanzado por el ejecutivo aprista en el caso de Accomarca. Estos nueve meses permitieron a Sendero Luminoso retomar y expandir la insurgencia en una zona de la cual habían sido en gran medida expulsados.

Al ver el desmesurado avance de Sendero Luminoso por prácticamente todo el territorio peruano, Alan García reculó en cuanto a las exigencias con las Fuerzas Armadas de que respetasen los derechos humanos y que acatasen las órdenes del ejecutivo. Nuevamente los comandantes volvían a tener todo el poder de decisión a la hora de elaborar las actuaciones militares y como debían llevarlas a cabo. 
El primer caso más sonado tras la vuelta de los militares fue en junio de 1986 con la "matanza en los penales del Perú", acaecidas en los penales de San Juan de Lurigancho, El Frontón y en la cárcel de mujeres de Santa Bárbara. En estas cárceles cumplían condena varios senderistas, se amotinaron haciendo presos a los guardias de las cárceles y a tres periodistas. La respuesta por parte de las fuerzas del Estado fue contundente, dejando la intervención contra los amotinados en torno a 133 víctimas mortales (https://peru21.pe/politica/caso-fronton-acusacion-fiscal-incluye-33-marinos-99563 29 de septiembre de 2018).

Los abusos contra los derechos humanos aumentaron considerablemente, se restringió todo acceso civil a las zonas declaradas de emergencia, incluso expulsaron a la Cruz Roja de la región de Ayacucho en 1988. El control militar en estas zonas era total. Los abusos siguieron sobre la población civil, el 14 de mayo de 1988 ocurrió la Masacre de Cayara, en el que un grupo de soldados masacraron a 39 campesinos de la comunidad campesina de Cayara (PARIONA, T. (18 de julio de 2017), Cayara, 29 años después, La República, recuperado de: https://larepublica.pe/politica/1062841-cayara-29-anosdespues), en represalia a una emboscada que llevó a cabo Sendero Luminoso a una patrulla del ejército el día anterior en la zona.

Durante los primeros años de Fujimori en el poder, se hicieron famosos grupos como el de Colina, el cual estaba integrado por militares y miembros de la Policía nacional. Este grupo fue el responsable de la masacre de Barrios Altos en Lima, donde fueron asesinadas 15 personas en noviembre de 1991 (República del Perú, 2003: 236). El grupo Colina también fue el artífice de la masacre de La Cantuta, el 18 de julio de 1992, en la Universidad Nacional de Educación Enrique Guzmán y Valle, el grupo Colina ejecutó a nueve estudiantes y un profesor, bajo la acusación de pertenecer a Sendero Luminoso (República del Perú, 2003: 236).

La violación de derechos humanos se hizo desgraciadamente habitual en la forma de proceder por parte de las Fuerzas Armadas durante el Fujimorismo, desde el primer momento que detenían a algún miembro o sospechoso de pertenecer a algún grupo terrorista, estas personas eran torturadas privándoles de uno o más de sus sentidos, la vista, los oídos o el habla durante un tiempo prolongado, todo ello para que el preso se derribara psicológicamente y acabase confesando. Durante este proceso además de privarle de sus sentidos los tenían maniatados o inmovilizados. 
Jugaban con los presos, les daban palizas, les insultaban, le amenazaban al detenido de que si no cooperaba, ellos les harían daño a sus familiares..

La lucha armada de confrontación directa en el Perú, acabó con la Operación Chavín de Huántar, llevada a cabo el 22 de abril de 1997, en la operación militar se llevó a cabo el rescate de los rehenes de la embajada japonesa en el Perú, hechos prisioneros por el MRTA. Las Fuerzas Armadas tomaron la embajada y mataron a los 14 miembros del MRTA que estaban dentro de la embajada, Sandoval (líder de la operación) perdió la vida en durante la operación, pero el resultado fue un éxito para Alberto Fujimori, a pesar de haber perdido dos militares de 142 que iniciaron la operación y un rehén en el rescate, rescataron a 72 rehenes. (Álvarez Rubio, 2015: 57 - 60)

\section{CONCLUSIONES}

La paz que se implantó en el Perú, fue una "paz imperfecta", como se ha visto, ésta llegó a través de la violencia sin control que vivió el pueblo peruano durante casi dos décadas. Dentro de la llamada historia de la paz, cuando se habla de "paz perfecta", es cuando ésta llega tras un proceso pacífico, en donde no haya habido violencia alguna. Cierto es, que esta premisa, y como ha ido evolucionando la humanidad hasta el día de hoy, parece una idea utópica, ya que en casi todos los procesos de paz, en algún momento ha habido algún acto violento.

Se debe buscar la paz dentro de lo que cabe lo más perfecta posible, al menos respetando todos los derechos humanos, algo que por desgracia no sucedió en el Perú.

No siempre la ofensiva militar y la estrategia de lucha contraterrorista deben estar siempre únicos y exclusivamente en manos de las fuerzas armadas de un país. Las fuerzas armadas son un actor imprescindible, pero también se debe intentar luchar contra el adversario mediante el diálogo, el consenso y sobre todo el talante.

La paz que se implantó en el Perú dejó muchas heridas abiertas, otras cerradas, que todavía buscan toda la justicia posible. La CVR elaborada en 2003, fue un gran avance para la búsqueda de la reconciliación 
nacional, seguida por la creación del archivo y museo histórico del LUM. Ciertamente, queda mucho camino por realizar, pero deben de seguir las medidas tomadas por los gobiernos post fujimorista y llevarlas más allá en la búsqueda por la reconciliación total de la sociedad peruana, una política que vaya en esa vía.

Solo por este camino, es posible acabar con los terroristas que quedan en la selva peruana y con los brotes senderistas que comienzan a verse por Lima, representados por el MOVADEF. Solo por el camino de la reconciliación se podrá acabar con movimientos como el MOVADEF, que solo busca dividir y sobre todo confundir a un núcleo de población peruana (sobre todo jóvenes) que no vivieron el horror de los años 1980 al 2000 en el Perú. Movimientos como los del MOVADEF deben ser combatidos con la verdad, con la paz.

El Perú debe encaminarse, que ya lo está haciendo con la famosa Ley 30470, Ley de búsqueda de personas desaparecidas durante el periodo de violencia 1980-2000, para acceder a una paz no ya perfecta, pero al menos acercase a la reconciliación con todo el pueblo peruano. En donde, todas las víctimas de esta lucha sean reconocidas, más que nada, para el reconocimiento de sus familiares, que en muchos casos, ellos no fueron culpables de las acciones del familiar desaparecido.

Las heridas, y el rencor siguen abiertas en muchos lugares del Perú, sobre todo en la zona donde el terrorismo tuvo mayor presencia, y en donde están operando en estos momentos, la zona del VRAEM, siguen todavía abiertas. Gran motivo es la sensación de abandono, el gobierno central por desgracia sigue descuidando en demasía el interior del país.

Estado peruano durante la contienda y la lucha contraterrorista dejó de lado los derechos humanos, quizás pensaron que no era época para sentimentalismos, sino para actuar con dureza contra el horror que estaban creando Sendero Luminoso y el MRTA en el Perú. 


\section{REFERENCIAS BIBLIOGRÁFICAS}

Álvarez Rubio, A. (2015). "La toma de rehenes como acto terrorista internacional. Análisis de la operación de rescate $<<$ Chavín de Huantar>>" en Revista de relaciones internacionales, estrategia y seguridad, vol.10, no2, pp. 43-68.

Burt, Jo-Marie (2011). Violencia y autoritarismo en el Perú. Bajo la sombra de Sendero y la dictadura de Fujimori. Lima: IEP.

Korsbaek, L., Sandoval Muro, C. y Salguero Haro, R. (1985). "La ronda campesina en una comunidad campesina en el norte de Perú: La Toma en Cajamarca", en investigaciones sociales, año XII n ${ }^{\circ} 20$, pp. 115-141.

Relva, H. (agosto de 2009). "El caso Fujimori, un hito histórico", en Amnistía Internacional, $\mathrm{n}^{\circ}$ 98, pp. 18-19.

Rodríguez Aguilar, C. (2007). Las rondas campesinas en el sur andino. Lima: SER.

Stern, J. S. (ed.) (1999). Los senderos insólitos del Perú. Guerra y sociedad, 1980-1995. Lima: IEP.

\section{FUENTES}

Archivo del museo del Lugar de la Memoria la Tolerancia y la Inclusión Social (LUM).

Archivo del Registro Único de Víctimas (RUV) de la UNESCO.

La República, 13 de septiembre de 1992.

La República, 17 de julio de 1992.

Ojo, 13 de septiembre de 1992.

Ojo, 17 de julio de 1992.

Página Libre, Lunes 09 de abril de 1990.

PARIONA, T. (18 de julio de 2017). Cayara, 29 años después, La República, recuperado de: https://larepublica.pe/politica/1062841-cayara-29anos-despues. 
República del Perú (2003). Comisión de la Verdad y Reconciliación. Informe final. Lima: CVR.

Revista OIGA, 12 de julio 1993.

\section{RECURSOS WEB}

http://lum.cultura.pe/cdi/busqueda/afectacion?a_ta=All\&a_anio $=\& a$ mes $=$ All\&a_dia $=\& a \_u b i c=A l l \&=$ Buscar2 de enero de 2017.2 de enero de $20 \overline{1} 7$.

http://lum.cultura.pe/cdi/busqueda4 de enero de 2017.

https://elcomercio.pe/politica/justicia/masacres-grandes-sendero-reciendescubriendo-399032 11 de septiembre de 2018.

https://peru21.pe/politica/caso-fronton-acusacion-fiscal-incluye-33marinos-9956329 de septiembre de 2018.

https://www.bbc.com/mundo/noticias-america-latina-37254469 29 de septiembre de 2018. 